\title{
ERRATUM
}

\section{Exposure to solar ultraviolet radiation in young Dutch children: Assessment by means of a 6-week retrospective questionnaire}

\author{
FABIAN TERMORSHUIZEN, ALET WIJGA, JOHAN GARSSEN, PETER N. DEN OUTER, HARRY SLAPER \\ AND HENK VAN LOVEREN
}

Journal of Exposure Analysis and Environmental Epidemiology (2002) 12, 204-213 doi:10.1038/sj.jea.7500220

Figure 2 of the above paper was published in black and white in error. The figure is reproduced below in colour.

2.a Daily median number of reported outdoor hours

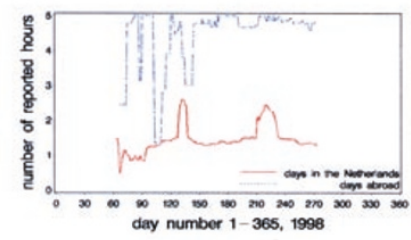

2.b Daily mean weighting factor for latitude \& season (L\&S)

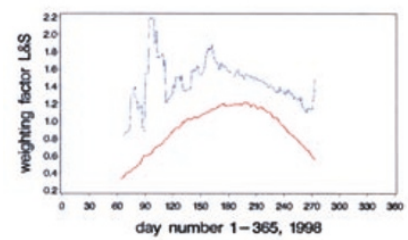

2.c Daily mean weighting factor for clothing (C)

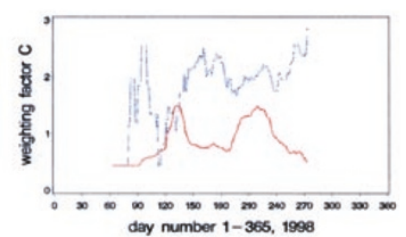

2.d Daily mean weighting factor for weather conditions as reported (WCq)

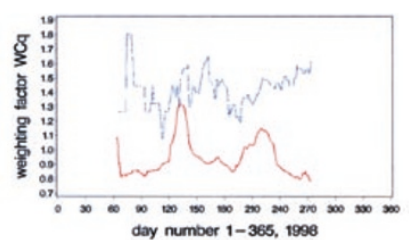

2.e Daily median number of outdoor hours weighted for L\&S

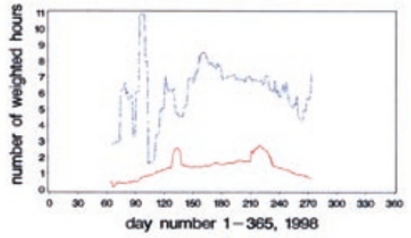

2.f Daily median number of outdoor hours weighted for L\&S and C

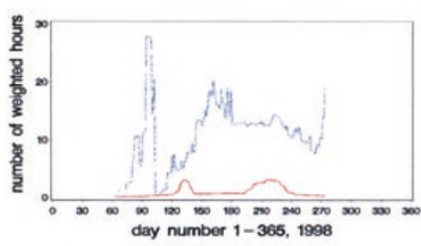

2.g Daily median number of hours weighted for $\mathrm{L} \& \mathrm{~S}, \mathrm{C}$, and $\mathrm{WCq}$

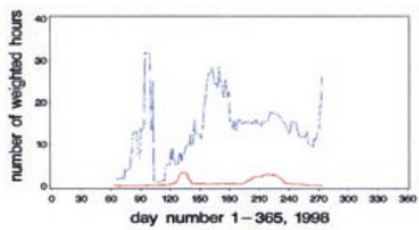

2.h Weather conditions in 1998 in Bilthoven (the Netherlands)

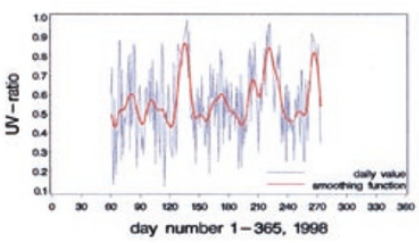

